\title{
EDITORIAL
}

\section{DERECHO POSITIVO VERSUS REALIDAD BIOLÓGICA: UNA REFLEXIÓN EN TORNO A LA FILIACIÓN}

\author{
BIOLOGICAL REALITY VERSUS POSITIVE LAW: \\ THOUGHTS ON FILIATION
}

DIREITO POSITIVO VERSUS REALIDADE BIOLÓGICA: UMA REFLEXÃO SOBRE A FILIAÇÃO

DOI: $10.5294 / D I K A .2014 .23 .2 .1$

Durante las últimas décadas, se ha podido comprobar cómo los avances de las nuevas tecnologias en el ámbito biomédico, especialmente las técnicas de reproducción asistida (TRA), han tenido una clara influencia en el ámbito del derecho, pues afectan a instituciones jurídicas básicas como el parentesco, el momento del nacimiento y de la muerte, la filiación, entre otras. ${ }^{1}$ Dicho influjo se ha venido reflejando, específicamente, en los ordenamientos jurídicos pertenecientes, en su mayoría, a la cultura occidental.

En un primer momento, las TRA fueron utilizadas como solución a los problemas de esterilidad de las parejas que deseaban tener hijos; sin embargo, en épocas recientes, estas técnicas también han sido empleadas en los casos en que una persona desea ser madre o padre soltero, y cuando parejas del mismo sexo desean tener hijos.

Por otra parte, la filiación es un término utilizado para describir la relación que existe entre padres e hijos. Como a todos los seres vivos, la dimensión sexual del ser humano le permite la procreación, pero a diferencia de las demás especies, los seres humanos

1 Cfr. María Dolores Vila-Colo, "El marco jurídico en la bioética”, en Cuadernos de Bioética, XVI (2005), pp. 313-321. 
se convierten en padres y madres, esposos y esposas, hijos e hijas, adquiriendo su propia identidad a través de los diferentes roles familiares. ${ }^{2}$ Por ello, la procreación no solo garantiza la perpetuación y la supervivencia de las sociedades humanas, sino que ha merecido su reconocimiento y protección por parte del derecho, ya que de ella se deriva la estructura social y natural del matrimonio, la familia, la paternidad, la maternidad y la filiación, instituciones que contribuyen de manera esencial al bien común de la sociedad. ${ }^{3}$ Siguiendo esta lógica, se observa cómo la filiación, en su origen, no es un fenómeno jurídico, sino una relación natural entre padres e hijos y, en este sentido, un fenómeno natural y social que precede a la ley.

Como es bien conocido, los orígenes jurídicos de la filiación radican en su reconocimiento por el derecho, como una estructura con una significativa utilidad social y pública. Mientras la maternidad podía ser determinada biológicamente porque "la madre siempre es conocida" (mater semper certa est), la paternidad fue establecida exclusivamente dentro del vínculo del matrimonio. El Código Civil Napoleónico — cuyos fundamentos se encuentran en el Derecho Romano y tuvo como heredera a gran parte de la cultura occidental - establecía que el hijo sería considerado legitimo si el padre y la madre estaban casados al momento de la concepción. ${ }^{4} \mathrm{Si}$ bien esta construcción legal de la paternidad reflejaba el orden social, también reflejó una cierta protección del padre para no ser legalmente vinculado con los hijos ilegitimos o naturales. Para este momento histórico, los aspectos más importantes de la paternidad fueron la transmisión del nombre, los derechos hereditarios y la nacionalidad. La adopción fue permitida pero solo para fines hereditarios.

En la década de los setenta, se produjo una fuerte crítica a este sistema debido a la forma en que los códigos civiles reconocían legalmente la filiación. La preferencia otorgada a la filiación legitima fue impugnada, sobre todo por el hecho de haberse convertido en un requerimiento puramente formal que dependía del consentimiento del padre. ${ }^{5}$ Como resultado, se inició en Europa una reforma de la estructura legal de la filiación que posteriormente se extendió por numerosos países. Esta reforma fue diseñada para poner fin a la distinción legal entre hijos legitimos e ilegitimos o naturales. De esta manera, se decidió que los hijos naturales debian recibir los mismos beneficios que los hijos legitimos. Este hecho fue particularmente importante porque favoreció el aspecto biológico sobre el matrimonio y el contrato. ${ }^{6}$

Cabe resaltar que a pesar de los aspectos controversiales para determinar la filiación, el derecho siempre ha buscado que la determinación legal de la paternidad

2 Francesco D’Agostino, Bioetica e Biopolitica: ventuno voci fondamentali, Torino, Giappichelli, 2011, p. 157.

3 Cfr. John FinNis, "Marriage, Justice and the Common Good", en Human Rights and Common Good, Oxford University Press, 2011. Claudio SARTEA, Biodiritto: fragilità e giustizia, Torino, Giappichelli, 2012, p. 70.

4 Camille RoBcis, The Law of Kinship: anthropology, psychoanalysis and the family in France, Cornell University Press, 2013, p. 23.

2185 Hernán CoRRAL, "Filiation and Assisted Reproductive Technology", Revue Générale de Droit (U. de Ottawa), 31 (2001), p. 6.

6 Camille RoBcis, The Law of Kinship: anthropology, psychoanalysis and the family in France, ob. cit., pp. 160-161. 
coincida, o al menos pueda coincidir, con la realidad biológica, ${ }^{7}$ incluido el vínculo ficticio que existe entre padres e hijos en el caso de la adopción.

El empleo de las TRA no tiene en cuenta el mencionado principio de la realidad biológica, que determinaría la paternidad y la maternidad de los donantes de gametos, por cuanto estas técnicas hacen posible la separación entre la procreación biológica y la filiación social. Con esta separación, el padre social ya no es necesariamente el padre biológico del hijo que espera su pareja. Sin embargo, socialmente hablando, esta situación no es nueva, ya que la adopción o el caso de los hijos nacidos fuera del matrimonio también reflejan este fenómeno. Lo novedoso está en la participación y colaboración de la ciencia y de la biotecnología en esta separación. ${ }^{8}$

Como podemos observar, las TRA han separado dos dimensiones que hasta entonces habian sido inseparables: la procreación como resultado de la unión sexual. Es decir, el hijo es el resultado de una serie de procedimientos tecnológicos y científicos, que no incluyen la unión conyugal. De esta forma, para la procreación o generación de un hijo se requeriría simplemente la colaboración de un padre genético, que aporta el espermatozoide y de una madre genética, que aporta el óvulo. Adicionalmente, podría ser requerida la colaboración de una madre por subrogación quien aporta su útero, y uno o dos padres adoptivos, socialmente reconocidos como padres del hijo. ${ }^{9}$ Estas circunstancias elevarían el número de posibles padres.

La separación entre la unión sexual y la capacidad de procrear también afecta a los lazos que unen al niño y a los padres en el proceso reproductivo. En el caso de la aplicación de la llamada "fecundación heteróloga", es decir, los procedimientos que implican la utilización de los gametos masculinos o femeninos de personas distintas de los aspirantes a ser padres, la paternidad o la maternidad biológica se disocia del niño resultante. Más allá de las disposiciones de la ley o de las decisiones de los jueces, la naturaleza del niño resulta dividida social y jurídicamente, ya que será la descendencia de alguien que no contribuyó en términos físicos en su constitución como un ser humano. Del mismo modo, la eventual intervención de una madre portadora conlleva un aspecto adicional de disociación que separa dos elementos de la biología de la reproducción: la contribución genética y la contribución de la gestación. ${ }^{10}$

Llegado este punto, es importante considerar que la generación de una vida humana, ya sea de forma natural o con la ayuda de la ciencia médica, no implica solamente la movilización eficiente de los gametos o un proceso fisiológico. También hay que tener en cuenta el contexto familiar, el bienestar psicológico y la

7 Javier Nanclares, "Reproducción asistida y doble maternidad por naturaleza", en Aranzadi CivilMercantil, 7 (2008).

8 Laurent Ravez, "Ethics and Medically Assisted Procreation: Reconsidering the Procreative Relationship", en Bioethics in the 21st Century, Croatia, InTech, 2011, p. 80.

9 Idem.

10 Hernán CoRral, "Filiation and Assisted Reproductive Technology", ob. cit.

DíkAion - ISSN 0120-8942, AÑo 28 - Vol. 23 Núm. 2 - Chía, Colombia - Diciembre 2014 
genealogia, que son factores determinantes para una relación familiar saludable y que no son tenidas en cuenta en el empleo de las TRA. ${ }^{11}$

El escenario descrito plantea algunos desafios en el ámbito del derecho, en particular para el concepto jurídico de filiación. Como se expuso anteriormente, antes de la aparición de las TRA, la filiación solo era posible por consanguinidad o por adopción, pero hoy en dia las cosas han cambiado, debido a que las parejas estériles no son las únicas usuarias de estas técnicas, sino también aquellos que desean ser padres solteros, o las parejas del mismo sexo que desean tener hijos. De acuerdo con estas circunstancias, se han creado nuevos tipos de filiación, como por ejemplo, el denominado "proyecto parental" o parental Project reconocido en Canadá, y la maternidad subrogada, legalmente permitida en países como India, Rusia y Estados Unidos.

Indudablemente, la casuística sobre la determinación de la filiación ha ido en aumento después de la aprobación del matrimonio entre personas del mismo sexo en algunos países. A primera vista, a pesar de que dos personas del mismo sexo puedan unirse legalmente, su descendencia será por adopción, pero no por consanguinidad, por lo menos para una de ellas.

Con el objeto de ilustrar cómo el derecho positivo ha ido cambiando la determinación de la filiación de acuerdo con estas nuevas formas de entender la paternidad y la maternidad, se mencionará brevemente el caso español, según el cual la Ley 14/2006 que regula las TRA fue modificada para que se determinara la filiación entre parejas del mismo sexo, sin necesidad de recurrir a un proceso de adopción.

Este es el caso de Antonia y María Ángeles, ${ }^{12}$ quienes contrajeron matrimonio poco después de haber entrado en vigor la Ley 13/2005, que permitió el matrimonio entre personas del mismo sexo en España. Tras someterse al procedimiento de reproducción asistida, María Ángeles quedó embarazada y tuvo una niña. Antonia fue a registrarla en el Libro de Familia correspondiente al Registro de Algeciras. En dicho registro le manifestaron que si queria constar también como madre legal de la menor debía primero adoptarla. Inconforme con la respuesta, Antonia se dirigió al Juzgado de Primera Instancia número 4 de Algeciras, que tiene las funciones de Registro Civil, y presentó allí su solicitud de registro como madre legal de la menor. La juez accedió a la petición y, de acuerdo con la normativa legal vigente, se realizó la inscripción de Antonia como Progenitor $B$ de la menor.

Como consecuencia de lo anterior, el Gobierno, tras las oportunas consultas a las autoridades competentes de los ministerios de Justicia y de Sanidad, manifestó que se revisaría la Ley 14/2006, que regula las TRA, con el objetivo de evitar la supuesta discriminación sufrida por los matrimonios de lesbianas que se someten a las técnicas de reproducción asistida, debido a que la madre no biológica estaría

11 Laurent Ravez, "Ethics and Medically Assisted Procreation: Reconsidering the Procreative Relationship”, ob. cit., p. 84.

12 Javier NANCLARES, "Reproducción asistida y doble maternidad por naturaleza", en Aranzadi Civil, 1 (2008). 
obligada a recurrir a un proceso de adopción para que en el Registro Civil conste como madre del menor, cosa que no ocurría en el supuesto de que el matrimonio fuera entre varón y mujer. En este último caso, la filiación se registra mediando, solamente, el consentimiento expreso del marido. ${ }^{13}$

De esta manera, la Ley 14/2006 fue modificada en su artículo 7, pues se le añadió un numeral tercero, cuya redacción es la siguiente: "Cuando la mujer estuviere casada, y no separada legalmente o de hecho, con otra mujer esta última podrá manifestar ante el Encargado del Registro Civil del domicilio conyugal, que consiente en que cuando nazca el hijo de su cónyuge, se determine a su favor la filiación respecto del nacido". ${ }^{14}$

En el caso descrito, llama la atención el hecho de que, a pesar de existir vías legales en el derecho español para dar solución a los problemas concretos de filiación por parte de parejas del mismo sexo, se haya preferido seguir el camino de la reforma legislativa para dar la misma solución a situaciones distintas, es decir, que se dé el mismo tratamiento jurídico a las cuestiones de filiación de parejas heterosexuales que a las de parejas homosexuales. De esta manera, se ponen en plano de igualdad situaciones que de hecho son diferentes. En primer lugar, se comparan parejas que pueden procrear y parejas que no pueden hacerlo. Así, se evidencia una instrumentalización del derecho positivo, según la cual "este únicamente tiene como función reglamentar situaciones particulares, susceptibles ellas mismas de ser contabilizadas. El derecho, evidentemente, debe tomar en cuenta las situaciones de hecho, pero no podría reducirse a esa función. La ley es general e impersonal; solo por aplicación de esta regla general permite resolver los problemas individuales". ${ }^{15}$ Por tanto, no "se hacen leyes para casos excepcionales. En materia de filiación, se legisla para la mayoría. Después, los casos particulares encuentran su solución por interpretación y adaptación de las reglas generales". ${ }^{16}$

Por otra parte, como se expuso anteriormente, se ha evidenciado que las modificaciones legislativas en materia de filiación lo que han buscado y han venido logrando, es que sea el aspecto volitivo, es decir, el "consentimiento", el factor determinante de la filiación. ${ }^{17}$ Esto ha contribuido a que se regule de manera uniforme y equivalente la filiación pretendida por parejas heterosexuales y parejas homosexuales. En definitiva, se busca que se reconozcan en el ámbito jurídico una serie de situaciones que en la realidad biológica de las personas son totalmente imposibles, tal y como sucede con la exigencia de reconocimiento de filiación natural (matrimonial) a parejas del mismo sexo.

13 Idem

14 BOE, núm. 65, 16 de marzo de 2005, p. 11253, en <http://www.boe.es/boe/dias/2007/03/16/ pdfs/A11251-11253.pdf> Fecha de consulta: 20 de marzo de 2012.

15 Xavier LACROIX, La confusión de géneros: respuesta a algunas demandas homosexuales sobre el matrimonio y la adopción, Bilbao, Mensajero, 2003, p. 56.

16 Ibid., p. 59.

17 Ana María VEGA, "Biotecnología y deconstrucción del género: algunas claves para comprender las politicas que afectan a la familia”, en Revista general de Derecho Canónico y Derecho Eclesiástico del Estado, 20 (2009), p. 19. 
Para concluir, podría afirmarse, en primer lugar, que las pretensiones de libertad procreativa absoluta, fomentadas por las TRA, disminuyen la conexión relacional entre padres e hijos. Mientras que las tecnologias pueden satisfacer el deseo de un hijo, los padres asumen que los deseos son derechos, y tratan a los hijos como bienes de consumo. En segundo lugar, mediante el derecho positivo se exige el reconocimiento de situaciones de filiación que tienen poco o nada que ver con la realidad, por lo menos con la realidad biológica de las personas. Como consecuencia, la definición jurídica de la filiación es cada vez más ajena a la naturaleza y, en su lugar, se sustenta en una preferencia explícita por una cultura de la autonomía.

MARTHA MIRANDA-NOVOA

Editora

martha.miranda@unisabana.edu.co 